\section{ACERCANDO LOS ARCHIVOS A LOS CIUDADANOS. UNA EXPERIENCIA DESDE EL PORTAL DE ARCHIVOS ESPAÑOLES (PARES) DEL MINISTERIO DE EDUCACIÓN, CULTURA Y DEPORTE ${ }^{1}$}

\author{
Alfonso Sánchez Mairena \\ Cuerpo Facultativo de Archiveros, Bibliotecarios y Arqueólogos \\ Área de Relaciones Institucionales \\ Ministerio de Educación, Cultura y Deporte \\ Secretaría de Estado de Cultura \\ Subdirección General de los Archivos Estatales \\ alfonso.sanchez@mecd.es
}

Cómo citar este artículo/Citation: Sánchez Mairena, A. (2014). "Acercando los archivos a los ciudadanos. Una experiencia desde el Portal de Archivos Españoles (PARES) del Ministerio de Educación, Cultura y Deporte". Arbor, 190 (765): a103. doi: http://dx.doi.org/10.3989/arbor.2014.765n1010

Recibido: 20 junio 2012. Aceptado: 15 septiembre 2012.

RESUMEN: El Portal de Archivos Españoles supone la tercera generación en la informatización de los Archivos Estatales. Está destinado a facilitar a los investigadores y a los ciudadanos el acceso integrado en red a las bases de datos archivísticas de los ocho grandes archivos de titularidad estatal distribuidos por la geografía española, al mismo tiempo que se van incorporando los facsímiles u objetos digitales de los documentos. Al mismo tiempo, PARES elabora una línea de herramientas para la gestión electrónica de los servicios públicos ofrecidos en la red de centros a los investigadores y ciudadanos que acceden presencialmente. $Y$ en tercer lugar, PARES es una plataforma destinada a favorecer todas las estrategias de difusión posibles. Fundamentalmente, la plataforma es a día de hoy un repositorio para la creación, gestión y difusión de los archivos históricos; no obstante, se encuentra en proceso de transformación para adecuarse a los conceptos de "archivos abiertos", al mismo tiempo que hacia los presupuestos de la Web 2.0. Para ello, se están llevando a cabo diferentes líneas de actuación como es la conversión de PARES en un repositorio OAI-PMH, que permita interoperar con otros sistemas de información archivístico, tanto españoles como internacionales; y se están elaborando nuevas herramientas y estándares para la incorporación de Puntos de Acceso multilingües.

PALABRAS CLAVE: Portal de Archivos Españoles (PARES); Servicios Públicos; Archivos estatales; Difusión; Acceso en línea; Bases de datos archivísticas; Gestión electrónica; Interoperabilidad; Puntos de acceso.

\section{BRINGING ARCHIVES TO THE PUBLIC. THE EXPERIENCE OF THE MINISTRY OF CULTURE'S SPANISH ARCHIVES PORTAL (PARES)}

Copyright: (C) 2014 CSIC. Este es un artículo de acceso abierto distribuido bajo los términos de la licencia Creative Commons Attribution-Non Commercial (by-nc) Spain 3.0.

ABSTRACT: The Spanish Archives Portal is the third generation in the computerization of the State Archives. It is intended to provide citizens and researchers with integrated on-line access to the archival databases of the eight state general archives distributed across Spain, while facsimiles or digital versions of the documents are added to the archival description catalogue. At the same time, PARES is producing a line of tools for electronic management of the public services offered in the network of the State Archives to researchers and members of the public visiting the archive in person. And thirdly, PARES is an archival platform intended to promote the whole range of possible dissemination strategies. The platform today is fundamentally a repository for the creation, management and dissemination of historical records. However, also it is involved in a process of transformation to accommodate the concepts of "open files" and web 2.0 principles. To do this, different courses of action are being pursued such as converting PARES into an OAI-PMH repository, which allows interoperability with other archival information systems, both Spanish and international, and the development of new tools and standards for the incorporating multilingual access Points.

KEYWORDS: Spanish Archives Portal (PARES); State Archives; Public Services; Diffusion; Access on line; Archival databases; Electronic management; Interoperability; Access points. 


\section{LA INFORMATIZACIÓN DE LOS ARCHIVOS ESTATALES: UNA TRADICIÓN EN LA MODERNIZACIÓN DE LOS VIEJOS ARCHIVOS}

El Portal de Archivos Españoles (PARES) [http://pares.mcu.es] es una plataforma informática archivística desarrollada por el Ministerio de Educación, Cultura y Deporte $^{2}$ con dos objetivos fundamentales. En primer lugar, crear, evolucionar y perfeccionar una plataforma de difusión en Internet para el Patrimonio Histórico Documental español, al mismo tiempo que proporcionar herramientas informáticas para la gestión electrónica de los servicios públicos archivísticos desarrollados en la red de archivos y centros que forman el sistema archivístico gestionado por la Secretaría de Estado de Cultura (Sánchez, 2008). Como otras plataformas, puede ser enfocada desde un doble punto de vista: el tecnológico y el archivístico. PARES es, de esta manera, una plataforma web destinada a la difusión en Internet, al mismo tiempo que una plataforma profesional interna de trabajo en red, que proporciona herramientas tanto para posibilitar el acceso on-line, como para la gestión de los servicios archivísticos y para el control de los fondos documentales de los archivos. Simultáneamente se debe procurar la conexión y cooperación con las líneas de actuación internacionales y nacionales. Proporciona así servicio a los archivos de titularidad estatal gestionados por el Ministerio de Educación Cultura y Deporte, que se encuentran distribuidos por la geografía española. Estos están apoyados por el Centro de Información Documental de Archivos [CIDA] y por el Servicio de Reproducción de Documentos de los Archivos Estatales [SRDAE]. En el conjunto de esta red se preservan y difunden unos $280 \mathrm{~km}$. de documentos, de los que casi la mitad se encuentran en el Archivo General de la Administración (AGA), ubicado en Alcalá de Henares (Madrid). Abarca documentos cuya noticia arranca del siglo VI hasta el año 2006, y, por tanto, están materializados en diferentes soportes documentales, expresados en distintas lenguas y sistemas escriturarios, producidos en diferentes contextos históricos; y distribuidos físicamente por diferentes provincias españolas.

PARES fue inaugurado en mayo de 2007, aunque su análisis y desarrollo comenzó en 2005. Desde una perspectiva temporal, nuestro portal supone lo que venimos conviniendo como tercera generación en el proceso de informatización de los Archivos Estatales, que hunde sus raíces en proyectos pioneros nacidos en los años 80, como la automatización de los protocolos notariales de los Archivos Históricos Provinciales, la elaboración de la base de datos integrada de la Guía de Fuentes Documentales y el Censo - Guía de Archivos. Pero el primer hito en la automatización de los archivos fue el denominado Proyecto de informatización del Archivo General de Indias, comenzado en la década de los ochenta e inaugurado en 1993 (González, 1999, p. 8) , $^{3}$ que ha supuesto todo un hito, dado que en la experiencia habida surgieron los primeros modelos de herramientas informáticas de gestión, descripción y difusión archivísticas (Oddos, 1994; Rütimann et al., 1992; González, 1999). En esta primera generación se crearon sistemas locales para la gestión electrónica de cada archivo, mediante la comercialización externa de unos programas informáticos concretos (Díez de los Ríos, 1996; Álvarez-Coca, 2010, p. 183; Álvarez-Coca et al., 2006, pp. 18, 28, 30-31). Es conveniente destacar que en los trabajos de análisis surgieron los primeros modelos formales de metadatos archivísticos que luego fueron evolucionados por el Consejo Internacional de Archivos (ICA/CIA) con la aparición de la primera norma de descripción general archivística destinada a permitir el intercambio normalizado de datos, la Norma ISAG (G): Norma Internacional General de Descripción Archivística (Ministerio de Cultura, 2000) ${ }^{4}$. El siguiente paso fue la conexión en red de todos los archivos mediante una plataforma integrada denominada Archivos Españoles en Red $(A E R)$, inaugurada en 2003. Esta segunda generación creó una arquitectura informática archivística que reforzaba la ecuación input-output para la creación y difusión de las bases de datos archivísticas y su difusión en Internet, que siguiendo con el esquema de la fase anterior, ampliaba la masa de información archivística normalizada a la que ir vinculando los diferentes proyectos de digitalización conforme a una serie de criterios de relevancia (De Santos y Desantes, 2004). La plataforma $A E R$ se integró tecnológicamente con el Censo-Guía de Archivos, y aunque la primera concentró sus esfuerzos a la integración de la descripción y la difusión de la red de Archivos estatales españoles, el Censo-Guía, por su parte, pasó a recibir, además de los sistemas archivísticos autonómicos y locales, y de diferentes instituciones archivísticas publicas y privadas, los contenidos procedentes de los archivos de Iberoamérica, producto de las actividades del Programa ADAl (Ayudas al Desarrollo Archivístico Iberoamericano) y del marco de cooperación institucional de la Secretaría de Estado de Cultura. El proyecto $A E R$ recibió reconocimientos internacionales a la labor de los archivos españoles (Desantes, 2004), así como severas críticas (González, 2003). No obstante, la apuesta de los Archivos Estatales españoles por la búsqueda de mayor visibilidad pública en Internet a través de $A E R$ produjo la creación y fidelización de una impor- 
tante comunidad internacional de usuarios virtuales, beneficiada por los logros del acceso on-line mediante la ruptura de las tradicionales barreras del acceso presencial a los archivos (Cruz y Sánchez, 2006).

La experiencia obtenida en estas fases precedentes llevó en 2005 a que el entonces Ministerio de Cultura apostara por la tercera generación de informatización a través del Portal de Archivos Españoles. Como plataforma de difusión, PARES evolucionaba hacia el concepto de Portal de Archivos Españoles, como un espacio en el que dar cabida con el tiempo a proyectos de difusión archivística de todo tipo, tanto los producidos por la red de archivos estatales, como por otras redes en un futuro a medio y largo plazo, conforme los marcos de cooperación fueran materializándose. PARES, además de permitir el acceso a las herramientas de interrogación de su base de datos de documentos digitalizados, ampliaba su espacio de difusión a las herramientas de referencias virtuales y de difusión electrónica, mediante el aprovechamiento otras bases de datos y exposiciones virtuales ya existentes y que eran objeto de interés por los clientes de la plataforma -investigadores, estudiantes, ciudadanos-. PARES surgió al mismo tiempo que entre 2005 y 2007 se creó el nuevo protocolo web institucional del Ministerio de Cultura, conforme a los requisitos de accesibilidad para discapacitados (WAI-AA - WCAG 1.0) definido para Contenido Web 1.0 del W3C, protocolo vigente actualmente. En este entorno, la plataforma PARES surgió como un micrositio web específico integrado en el mosaico de la web institucional de la Secretaría de Estado de Cultura.

Por tanto, los principales objetivos marcados institucionalmente para PARES consisten en la creación de un portal especializado en archivos históricos generales para su difusión archivística en Internet, al mismo tiempo que sea una plataforma profesional de trabajo interno en red (Intrapares), que provea de herramientas para la gestión electrónica de los servicios públicos archivísticos, y permita la atención de calidad a los usuarios de los archivos -clientes presenciales- y a través de la propia plataforma -clientes virtuales-. Simultáneamente, nuestro portal archivístico debe evolucionar para converger con las principales líneas de cooperación nacional e internacional en materia de archivos. Por ello, PARES debe ser progresivamente el reflejo de las buenas prácticas y de los procesos de normalización archivística. Y consecuentemente la gestión normalizada de los servicios archivísticos debe materializarse en el uso de herramientas comunes, avanzado hacia la gestión de procesos y trámites co- munes en toda la red de archivos. Pero, sobre todo, PARES ha de evolucionar fundamentalmente hacia una tecnología de archivos abiertos, cuyos contenidos puedan ser recolectados por los principales motores de búsqueda en Internet y sus contenidos ser aprovechados por la amplia comunidad de usuarios existente.

En 2007, PARES ofreció el libre acceso on-line a su base de datos, tras la supresión legal de la antigua TNI (Tarjeta Nacional de Investigador), que había condicionado el acceso controlado en $A E R$, mediante el registro previo y la obtención de unos códigos de acceso (login de usuario y contraseña) ${ }^{5}$. A pesar de la lógica legal que tenía este acceso controlado, los nuevos investigadores vía Internet lo consideraron, en muchas ocasiones, más como un obstáculo que como un servicio acorde con la innovación del acceso en línea desde Internet (Carabias, 2009, p. 374). En PARES el registro previo es solo obligado para los profesionales que trabajan en la fase interna, debido a los necesarios requisitos de control y estadística; y en el acceso presencial a los archivos, cuando se hace desde el módulo de gestión interna de archivos. El usuario de PARES en Internet no necesita registro previo y su acceso es libre, haciéndolo siempre a información que no debe tener ninguna restricción legal o de propiedad intelectual, publicada en PARES por los distintos archivos.

Investigadores, estudiantes y ciudadanos acceden a una representación electrónica de los documentos mediante su reflejo en unidades de descripción archivística articuladas en campos o metadatos archivísticos normalizados según la Norma ISAD (G). Estas unidades de información archivística son las que tienen vinculadas las imágenes digitalizadas del documento original, cuyos criterios selectivos obedecen a determinadas recomendaciones y buenas prácticas inspiradas en la preservación y la difusión digital (Cruz y Sánchez, 2006, pp. 38-39). Todo el conjunto de facsímiles digitalizados que representan a un mismo documento forman parte de un objeto digital que puede ser usado directamente, impreso, guardado o exportado de la plataforma mediante distintas estrategias.

Es de justicia indicar que la evolución de la informatización de los Archivos de titularidad estatal gestionados por el Ministerio de Educación, Cultura y Deporte refleja el esfuerzo y la apuesta del conjunto de los profesionales que los gestionan y que trabajan en ellos, dedicados a la elaboración y difusión de contenidos culturales archivísticos de calidad en el mundo de Internet. Un medio este que manifiesta un curioso fenómeno de evolución perfectiva, dada la rápida obsolescencia de 
las tecnologías en un entorno virtual cambiante, junto a la proliferación saturadora de los denominados contenidos basura y las problemáticas de la transmisión del conocimiento, que en conjunto suponen un constante y severo reto para generar y satisfacer a una creciente comunidad de lectores e investigadores virtuales en su mayor parte. A día de hoy, los Archivos Estatales han conseguido con su esfuerzo constante aumentar la visibilidad profesional como gestores de servicios públicos demandados en la red de centros difundidos en PARES se muestra en la tabla I.

Los conceptos de integración, escalabilidad e interoperabilidad que se han ido generando en las diferentes generaciones del proceso de informatización de los Archivos Estatales permiten actualmente definir PARES como una plataforma integrada por diferentes aplicaciones como son el Portal de Archivos Españoles, el Censo-Guía de Archivos de España e Iberoamérica y diferentes micrositios web especializados. Este complejo a día de hoy está comenzando la interoperabilidad con proyectos internacionales como el Portal de Archivos Europeos (APEx: Archives Portal Europe network for excellence $)^{6}$, EUROPEANA ${ }^{7}$ y MONASTERIUM ${ }^{8}$, este a través del Proyecto ICARUS y la Fundación ENArc. Las principales líneas de actuación evolucionan de forma sinérgica, compartiendo Puntos de Accesos y Registros de Autoridades, Registros descriptivos documentales para diferentes funciones, así como la provisión de estos últimos a APEx mediante una pasarela de archivos abiertos. PARES comparte con el Censo-Guía la información referida a macrodescripción, es decir, fondo, colección y serie con sus divisiones, mientras que obtiene de ese instrumento la información referida al nivel de archivo como institución.
Jurídicamente en la reciente regulación del Sistema Español de Archivos de la Administración General del Estado (Real Decreto 1708/2011, de 18 de noviembre; BOE no 284 de 25/11/2011) el Portal de Archivos Españoles tiene como finalidad primordial la difusión en Internet de las bases de datos descriptivas y de los bancos de objetos digitales que recrean los documentos de la red de archivos del Ministerio de Educación, Cultura y Deportes, fomentándose el máximo acceso libre y gratuito a los ciudadanos (art.o 19.a). De la misma manera, inicia un marco jurídico para que otros archivos del Sistema Español de Archivos se adhieran a la plataforma PARES, indicación que incide en la evolución de nuestro portal hacia una infraestructura de archivos abiertos que permita el intercambio de información bidireccional con otros archivos dentro y fuera de España.

\section{PARES: UNA PLATAFORMA INFORMÁTICA PARA GESTIONAR LOS SERVICIOS PÚBLICOS ARCHIVÍSTICOS Y PARA DIFUNDIR Y ACCEDER ELECTRÓNICAMENTE AL PATRIMONIO DOCUMENTAL DE ESPAÑA}

El acceso a PARES se realiza de diferentes maneras, utilizándose cualquiera de los navegadores usuales:

1. Mediante la URL del propio micrositio 9 .

2. Usando los enlaces directos que aparecen en el portal web de la Secretaría de Estado de Cultura ${ }^{10}$ y en el micrositio de la Subdirección General de los Archivos Estatales ${ }^{11}$.

3. A partir del micrositio web de cualquiera de los Archivos Estatales ${ }^{12}$.

Tabla I

\begin{tabular}{|l|c|c|}
\hline \multicolumn{1}{|c|}{ Archivo / Centro* } & Acrónimo & Localización \\
\hline Subdirección General de los Archivos Estatales & SGAE & Ministerio de Cultura. Madrid \\
\hline Archivo General de la Administración & AGA & Alcalá de Henares (Madrid) \\
\hline Archivo Histórico Nacional & AHN & Madrid \\
\hline Archivo General de Indias & AGI & Sevilla \\
\hline Archivo General de Simancas & AGS & Simancas (Valladolid) \\
\hline Archivo de la Corona de Aragón & ACA & Valladolid \\
\hline Archivo de la Real Chancillería de Valladolid & ARCHV & Salamanca \\
\hline Centro Documental de la Memoria Histórica & CDMH & Toledo \\
\hline Sección Nobleza del Archivo Histórico Nacional & SNAHN & Ministerio de Cultura. Madrid \\
\hline Archivo Central del Ministerio de Cultura & ACMCU & Alcalá de Henares (Madrid). \\
\hline Centro de Información Documental de Archivos & CIDA & Madrid \\
\hline $\begin{array}{l}\text { Servicio de Reproducción de Documentos de los Archivos } \\
\text { Estatales }\end{array}$ & SRDAE & . \\
\hline
\end{tabular}

* En el año 2010 fue transferida la gestión de los tres archivos históricos provinciales del País Vasco a la Comunidad Autónoma de Euskadi. De momento, los fondos descritos y digitalizados en los caso de Álava / Araba y Guipúzcoa / Gipuzkoa se mantienen en difusión en el Portal de Archivos Españoles. 
PARES ha sido producido mediante un desarrollo modular por generaciones de herramientas, así como del perfeccionamiento de las existentes, lo cual permite su escalabilidad. Desde el doble punto de vista tecnológico y archivístico, PARES es una aplicación web específica de archivos on-line. La infraestructura ha sido diseñada de forma centralizada con base en la Subdirección General de los Archivos Estatales, desde el punto de vista de los procesos de mantenimiento y seguridad; aunque la gestión de datos y servicios está diferenciada por cada uno de los archivos integrantes de la red; es decir, cada archivo actúa y gestiona en su propio ámbito. Estamos ante un modelo de centralización de la infraestructura, de integración de la información, de difusión integrada y de gestión distribuida de la misma y de los servicios archivísticos, en virtud de diferentes perfiles y capacidades dentro de cada archivo. La base de datos de PARES presenta unas características específicas, puesto que partiendo de un producto estándar de mercado como Oracle, la plataforma ha evolucionado hacia herramientas optimizadas y especializadas archivísticamente para usos y fines de indagación y difusión específicos. Tecnológicamente PARES es un sistema optimizado para una gestión ágil de los datos y las imágenes vinculadas en un entorno de relaciones múltiples en tiempo real. Las búsquedas ofrecen los resultados de forma suficientemente rápida. Independientemente de que la arquitectura informática está basada en el citado producto de mercado y en su gestor de base de datos
(Oracle text), el resto de herramientas que articulan PARES están basados en la filosofía del software libre. Nuestra plataforma es un programa propietario del Ministerio de Educación, Cultura y Deporte, articulada en módulos cuyos desarrollos diferenciados se elaboran externalizadamente por diferentes empresas que concurren mediante el sistema de concurso público. La coordinación informática la realiza la Subdirección General de Tecnologías de la Información y Comunicación, y la archivística por la Subdirección General de los Archivos Estatales.

La integración de los datos y las imágenes, así como la centralización tecnológica tiene ventajas desde el punto de vista del programa de copias de seguridad, securización de la plataforma, de los procesos de migración, de ampliación de infraestructura o de la actualización de versiones, liberando a los archivos de estas tareas, al mismo tiempo que se les presta constante apoyo técnico. Pero muy especialmente se ofrece una clara ventaja de cara a facilitar los procesos de normalización de la información archivística y de la gestión de manera que se agilizan los procesos de contribución y cooperación con los programas de actuación internacionales como, por ejemplo, APEnet, el Portal de Archivos Europeos. Ello no impide la gestión en cada archivo con sus propias particularidades.

El desarrollo modular de PARES se vertebra en dos grandes fases, articuladas a su vez por diferentes herramientas, según el siguiente esquema:

\section{Tabla II}

\begin{tabular}{|c|c|}
\hline PARES & INTRAPARES \\
\hline $\begin{array}{l}\text { Acceso "desde la red" (on-line). } \\
\text { Entorno de difusión y libre acceso. } \\
\text { 1. Herramientas de Acceso en red: } \\
\text { a. Buscador (Sencillo / Avanzado) } \\
\text { b. Inventario Dinámico. } \\
\text { 2. Herramientas para las Referencias virtuales y la } \\
\text { difusión: } \\
\text { a. Contacte. } \\
\text { b. Novedades y artículos informativos. } \\
\text { c. RSS. } \\
\text { d. Lista distribución } \\
\text { e. Micrositios Web monográficos. } \\
\text { f. Enlaces a recursos de información. } \\
\text { g. Vídeo. } \\
\text { h. Facebook. }\end{array}$ & $\begin{array}{l}\text { Acceso "dentro de la red" (in-line). } \\
\text { Entorno de trabajo interno con acceso controlado según } \\
\text { perfiles y capacidades por herramientas, en virtud del grado } \\
\text { de responsabilidad. } \\
\text { 1. Módulo de búsquedas integrado. } \\
\text { 2. Módulo de Administración de usuarios internos. } \\
\text { 3. Módulo de Gestión interna de archivos: } \\
\text { a. Registro general de investigadores. } \\
\text { b. Salas de investigación. } \\
\text { c. Reprografía. } \\
\text { 4. Control de fondos (v1). } \\
\text { 5. Módulo de Descripción: } \\
\text { a. Unidades descriptivas de documentos. } \\
\text { b. Puntos de Acceso y Autoridades. } \\
\text { c. Revisión. } \\
\text { 6. Módulo de Estadísticas. }\end{array}$ \\
\hline
\end{tabular}




\section{Las herramientas de PARES}

Esta fase de la plataforma es accesible en Internet. Su objetivo es proporcionar acceso a los archivos a los ciudadanos e investigadores mediante el acceso en red, al mismo tiempo que permitir estrategias de difusión virtual. La web de PARES está articulada por diferentes métodos de acceso a la información archivística, complementada por distintas herramientas de comunicación e información, que permiten una estrategia de difusión con amplias posibilidades. Esta metodología se refleja en la propia arquitectura de la web del portal de acceso.

PARES permite el acceso a dos niveles de información relevantes: por un lado, el acceso en red a la información archivística y, por otro, a las herramientas de referencias virtuales. Por tanto, el portal actúa como un punto de acceso general a diferentes generaciones de información propia y otra complementaria obtenida mediante hipervínculo o enlace desde otros espacios virtuales de los Archivos Estatales.

Las búsquedas se realizan mediante dos métodos distintos, un buscador sencillo y otro avanzado. El primero de ellos consiste en una herramienta que permite interrogar a la base de datos integrada por las aportaciones de nueve de los diez archivos conectados en red $^{13}$, mediante la escritura de términos en lenguaje natural, que pueden acotarse mediante filtros por fechas, y además permite recolectar de forma diferenciada los registros digitalizados, los que no lo están o tanto unos como otros. Las órdenes de búsqueda si se escriben entrecomilladas se convierten en órdenes literales de la cadena de palabras indicada, es decir, son búsquedas exactas. Por tanto, no se obtendrán el mismo número de resultados si escribimos, por ejemplo, "Cristóbal Colón" entrecomillado o no, siendo más precisas las estrategias entrecomilladas. El sistema ofrece una lista de resultados que en este caso se limita a los cien resultados más relevantes. Es una excelente herramienta para realizar sondeos acerca de cualquier término y conocer la existencia de documentos relacionados y distribuidos por diferentes fondos y series documentales dentro de un mismo archivo y por toda la red de archivos.

Cuando el usuario necesite profundizar más en sus búsquedas cuenta con el buscador avanzado, que parte de los elementos del buscador sencillo, enriquecido con nuevos parámetros de indagación. De esta manera, el investigador puede restringir una orden de búsqueda a un archivo concreto y dentro de este puede centrar su estrategia en los primeros ni- veles de organización de los cuadros de clasificación y dentro de ellos hasta el nivel de fondo documental. Los buscadores operan independientemente de que escribamos los términos con mayúscula o minúscula, acentuados o no, el único requisito consiste en que las palabras tengan como mínimo tres caracteres (por ejemplo, "Tuy"); el sistema discrimina los artículos, las conjunciones y las preposiciones, que solo son tenidas en cuenta para la construcción de una cadena de palabras exactas mediante entrecomillado.

Complementariamente se puede utilizar una búsqueda por signatura, seleccionando previamente un archivo de la lista desplegable en el que operar, de manera que el sistema cargue su esquema de signaturas, a partir del cual se puede seleccionar una en concreto, para que el sistema nos lleve directamente al documento. También se puede escribir directamente una signatura en el campo, pero es necesario que el investigador la edite exactamente igual a como está introducida en el sistema, dado que una diferencia en un espacio, en una mayúscula u otro elemento tipográfico no son reconocidas por el buscador. Las búsquedas por signaturas pueden ser exactas o por signatura incompleta, lo cual permite acceder en el caso de las primeras exclusivamente al documento indicado, y en las segundas a todos los documentos que integran, por ejemplo, una unidad de instalación (caja, legajo o carpeta).

El siguiente nivel de búsqueda consiste en una estrategia por encabezamientos de índices de materias, onomásticos, geográficos o de instituciones. Esta operación proporciona un nivel de acceso complementario a los anteriores, basados en la búsqueda a texto general, en virtud del diferente nivel de análisis documental que proporcionan los puntos de acceso. En esta primera fase de PARES no se permite el acceso a las listas de encabezamientos, dado que los Archivos Estatales se encuentran en fase de normalización y depuración de las bases de datos de índices heredadas, especialmente a partir de la publicación de la primera norma en este sentido, que tuvo lugar en septiembre de 2010; situación que será superada en próximas versiones.

La búsqueda avanzada ofrece un mayor número de resultados respecto a la búsqueda sencilla, aunque el volumen creciente de la base de datos integrada de PARES plantea problemas a la hora de recolectar la totalidad de los documentos vinculados a una orden de búsqueda en virtud del grado de sencillez de la misma. Por ejemplo, si indagamos la base de datos con órdenes intuitivas para un usuario normal, como un apellido o un topónimo como Madrid, que esta- 
ría presente en más de un millón de registros documentales, el sistema responderá con una pantalla que orienta al usuario para que acote y precise su búsqueda para poder afinar y obtener resultados más pre$\operatorname{cisos}^{14}$. Esta es una de las principales problemáticas, no exclusiva de PARES, sino de todas las plataformas integradas que se están gestando en estos momentos, dotadas de millones de registros y donde el tema de la alfabetización informacional y la web semántica son claves estratégicas que hay que incorporar.

Existen, por tanto, tres estrategias diferenciadas de búsqueda:

a. En la primera, el motor de búsqueda opera básicamente sobre los campos del formulario archivístico basado en la norma ISAD (G). Existe una búsqueda a texto completo por los campos que permiten este tipo de edición como "Título", "Alcance y contenido", "Notas" y otros similares. Sobre esta estrategia se establecen filtros basados en otros campos y elementos como los de "Fecha(s)", "Archivo", "Nivel descriptivo" o "Reprografía digital".

b. En la segunda, se opera directamente sobre la entidad "Signatura".

c. Y, en la tercera, sobre la lista de índices de encabezamientos de materias, personas, lugares o instituciones (Puntos de Acceso).

Estas estrategias serán perfeccionadas en próximas versiones, donde se mejorará especialmente la búsqueda y navegación por Puntos de Acceso normalizados, que atenderá tanto al Registro de Autoridades archivísticas como a los Puntos de Acceso específicos de encabezamientos de lugares, de personas, de instituciones y de materias, que irán evolucionando hasta incorporar accesos tesaurizados, conforme la información elaborada en PARES, así como la heredada de las generaciones anteriores, estén normalizadas conforme al nuevo estándar. El investigador y usuario de PARES cuenta con ayudas detalladas que explican cómo operar y sacar el mayor rendimiento a estas herramientas.

Los resultados son proporcionados mediante una navegación que permite llegar a la imagen digitalizada de un documento, o a su unidad descriptiva, en un máximo de tres pulsaciones con el ratón. Se ofrecen estructurados por archivos de procedencia y, dentro de estos, por los niveles de macrodescripción (fondos, series y colecciones documentales y sus equivalentes como las divisiones de fondos y de series) $)^{15}$ que son co- munes a las unidades de descripción pertinentes con la orden de búsqueda. Esta estrategia está condicionada por la existencia actual de hasta dieciséis niveles de descripción posibles que pueden contextualizar a una unidad documental ${ }^{16}$. PARES proporciona el acceso directo a las unidades documentales y a su facsímil digital, mientras que el acceso al contexto jerárquico del documento dentro del archivo se obtiene mediante dos estrategias. Una huella o rastro en la parte superior de la pantalla informa acerca de la orden de búsqueda, del archivo al que pertenece el documento y acerca de la unidad de macrodescripción a la está vinculado el mismo (fondo, serie, colección). En este último caso mediante hipervínculo se puede acceder a la información del fondo o la serie a que esté vinculado el documento, permitiendo PARES acceso al contenido de todos los nodos documentales completos mediante la opción "Contiene". Esta es una operativa compartida con el Inventario Dinámico. En segundo lugar, a partir de pulsar la opción "Ver" en la unidad descriptiva el sistema proporciona el esquema multinivel al que pertenece la unidad documental. Es decir, obtenemos una doble representación del "Código de referencia"17 y su equivalente en el contexto jerárquico en el que tiene sentido la unidad documental.

Los buscadores de PARES, como hemos indicado, permiten el acceso a los registros descriptivos en su doble dimensión, como unidad documental o como inserta en un contexto archivístico, junto a las imágenes digitalizadas de los mismos. La información ofrecida está representada por un formulario descriptivo basado en la Norma ISAD (G), que analiza y representa los caracteres internos y externos del documento, de la serie o del fondo. Dependiendo de la estrategia de descripción realizada por el correspondiente archivo, podremos acceder a descripciones someras que contienen los seis campos mínimos obligatorios establecidos $^{18} \mathrm{o}$ a descripciones analíticas dotadas de un mayor nivel de información y detalle. Esto dependerá de la estrategia de descripción utilizada por el archivo correspondiente. La base de datos de PARES ofrece registros descriptivos de documentos que pueden estar digitalizados o no; se viene primando el ofrecer el máximo de información descriptiva para que el usuario pueda conocer la existencia y localizar el máximo número de documentos posible, de manera que, a partir de las descripciones de PARES, pueda consultar los originales en los archivos o solicitar copia de los mismos. El proceso de digitalización es, sin embargo, más selectivo, dado que se eligen los fondos, series y colecciones documentales en virtud de criterios concretos como pueda ser la antigüedad de los manuscri- 
tos para evitar su deterioro por la excesiva manipulación del original, la alta demanda por la comunidad investigadora o la importancia de la información registrada en virtud de la celebración de aniversarios, exposiciones u otro tipo de eventos (Grupo de Expertos IFLA/ICA, 2005: 32-39). El órgano encargado de la digitalización es el Servicio de Reproducción de Documentos de los Archivos Estatales (SRDAE).

Asociadas a los buscadores, PARES ofrece dos interesantes herramientas como son el "Envío telemático" y la "Agenda" del investigador ${ }^{19}$. El primero permite la exportación de fragmentos de seis imágenes que elige el usuario dentro del objeto digitalizado de un documento y las puede exportar vía correo electrónico. La exportación se realiza en formato pdf que tiene incorporada información legal sobre el buen uso de la información gratuitamente conseguida, especialmente destinada a fines de autoformación e investigación, recomendándose el no uso a terceros con otros fines y la cita de procedencia de las imágenes del documento, archivo y signatura, fundamentalmente. PARES permite la descarga de las imágenes desde su editor, así como la impresión directa de las mismas y de los registros descriptivos. Por su parte, la "Agenda" es una herramienta que permite a los usuarios guardar los registros documentales que seleccione durante sus búsquedas en un espacio reservado que previamente han registrado, sin necesidad de proporcionar datos personales obligatoriamente, y conservarlos por un período máximo de tres meses, que se renueva automáticamente cada vez que el usuario accede a la "Agenda". En ella, puede realizar anotaciones, gestionar espacios temáticos personalizados y exportar vía correo electrónico su contenido. La exportación permite acceder a los títulos de los documentos que actúan como hipervínculos que llevan al usuario de nuevo a PARES para leerlos, imprimirlos, exportarlos o incorporarse a la navegación por la plataforma. Por directriz corporativa, todas las imágenes llevan una marca de agua que se hereda en las exportaciones, destinada a referenciar las imágenes de cara a los usos descontrolados de las mismas. La marca permite normalmente la lectura de los documentos y en caso de necesidad para la investigación el usuario, como viene siendo habitual, puede contactar con el archivo de referencia y solicitar la reprografía de las mismas.

Cuando un documento está digitalizado el sistema lo avisa mediante un icono de cámara fotográfica situado en la parte derecha de las listas de resultados, o mediante un botón específico titulado "Ver imáge- nes" situado en la unidad descriptiva. Para acceder a la lectura de los facsímiles, PARES proporciona una herramienta de edición propia, a la cual se accede activando los dos sistemas anteriores. La herramienta en este caso nos ofrece el objeto digital, entendido como la suma de imágenes que representan un documento mediante reprografía digital. Permite también aplicar operaciones sencillas de tratamiento de imágenes como aumento y disminución del tamaño, rotación, contraste de brillo y polaridad; también se puede imprimir y exportar cada imagen y navegar por las mismas. Cada facsímil digitalizado de un documento tiene una doble etiqueta, dotada por un elemento que indica la secuencia ordenada que es útil para indicar la impresión o la exportación vía "Envío telemático"; a lo que se asocia un número que permite a los archivos incorporar la foliación, paginación u otras representaciones codicológicas. Ambos elementos son complementarios, pues en muchos casos pueden no coincidir en su secuencia, debido a que se hayan reprografiado dobles páginas, se hayan omitido páginas en blanco o se hayan incorporado ampliaciones de miniaturas, entre otras casuísticas. En el caso de la digitalización de una unidad de instalación (caja, legajo, carpeta), PARES permite establecer dentro del mismo objeto digital bloques específicos a cada unidad documental. En la parte superior de la pantalla se ofrece información descriptiva esencial para que el usuario pueda referenciar al documento que está leyendo virtualmente (archivo, signatura y título).

Además de los buscadores, PARES ofrece una Guía electrónica denominada "Inventario dinámico", debido a que la información está constantemente siendo actualizada, mediante procesos de publicación y modificación correctiva por parte de los archivos. En Internet PARES permite el acceso a los documentos que exclusivamente están catalogados como accesibles, permaneciendo dentro del sistema todos los registros que son migrados y grabados, pendientes de procesos de revisión y control de calidad por los responsables de descripción de cada centro. Esta Guía electrónica proporciona información real en estado publicado de todos los fondos documentales de un archivo dado que están informatizados y disponibles para su consulta en PARES. Mediante un sencillo sistema de iconos que activa internamente cada archivo, el usuario puede conocer qué fondos o series documentales están total o parcialmente descritos o digitalizados. Esta guía permite acceder a la información, previa selección de un archivo concreto, y enlazar directamente a su micrositio web. Mediante 
un sencillo sistema de filtrado a partir del cuadro de clasificación, existe una herramienta de "Novedades" que ofrece el acceso a todas aquellas unidades de descripción en cualquier nivel que hayan sido publicadas, modificadas en su contenido o hayan sido objeto de vinculación de imágenes digitalizadas. La presentación de la información es multinivel y jerarquizada conforme a los cuadros de clasificación de cada archivo.

Tanto en la lista de resultados del inventario dinámico como en los ubicados en la lista de registros dependientes de una unidad de macrodescripción, mediante la opción "Contiene", el sistema ofrece la posibilidad de realizar filtros recurrentes sobre la lista de resultados documentales, operando sobre los campos "Alcance y contenido" y "Título(s)". Dado que la lista de resultados puede recolectar documentos ubicados en distintos niveles por debajo de la unidad superior representada en la primera pantalla de resultados, PARES ofrece también la posibilidad de volver a filtrar los resultados por uno de los "Niveles inferiores" de descripción.

Si hacemos una comparación entre el acceso tradicional presencial a los archivos y el virtual a través de plataformas electrónicas integradas como PARES, observamos cómo los buscadores y el inventario dinámico proporcionan funciones que han dado tradicionalmente los diferentes instrumentos de descripción, de control y difusión. Estos han sido tradicionalmente elaborados en relación a cada uno de los fondos o series documentales a que se referían, habiéndose creado interesantes y voluminosas bibliotecas especializadas en instrumentos de referencias. Sin embargo, una plataforma integrada como la nuestra funciona en virtud de una lógica parecida a un gran inventario por cada uno de los archivos, articulado por sus diferentes fondos, series y colecciones documentales. Cada nodo de información -por ejemplo, una serie y todos los documentos vinculados a ella- equivale a un inventario tradicional. Las estrategias de búsqueda funcionan con la misma lógica de los tradicionales índices de encabezamientos de materias, onomásticos, geográficos o de instituciones; aunque los buscadores electrónicos permiten enriquecer las estrategias de búsquedas con términos complejos y extensos, cadenas de palabras entrecomilladas y la aplicación de diferentes filtros. El resultado es siempre una lista de resultados y esta vendría a funcionar como los tradicionales catálogos, aquellos donde podemos obtener las referencias a documentos vinculados por el criterio subjetivo con el que se realizó el catálogo (Arroyal-Martín, 1991, 101-118).

\section{Las herramientas de Intrapares}

A este entorno de trabajo interno de PARES los usuarios acceden mediante su registro e identificación previos en el sistema. Está articulado por una serie de módulos, dotados a su vez de diferentes herramientas, todos ellos interconectados entre sí.

Siguiendo el orden lógico del acceso y la gestión de la información, tenemos en primer lugar un módulo para la administración de usuarios internos. Este módulo está supervisado por la Administración de PARES (Superadministrador), que crea a los Administradores de cada archivo. Estos se encargan de gestionar los perfiles de los diferentes usuarios, conforme a las buenas prácticas obligadas en el manejo de bases de datos personales, que coordinadamente con la dirección de los centros debe proporcionar acceso a las diferentes herramientas en virtud de la función y la responsabilidad que haya que ejercer. Estos perfiles van desde el de director de archivo, pasando por los de revisión, hasta llegar a los de grabador o usuario esencial de las herramientas.

Para la elaboración, control y gestión de las bases de datos descriptivas existe un módulo de descripción, articulado a su vez en diferentes bases de datos relacionadas (Unidades de descripción, Signaturas, Productores archivísticos y Puntos de acceso), que están complementados por una potente herramienta de revisión que permite buscar, editar, publicar, exportar y efectuar operaciones de modificación masiva en virtud de los perfiles y capacidades de cada usuario. Existe un entorno de pruebas que replica la información, donde se editan las remesas de migraciones de datos para elaborar controles de calidad previos, y para practicar operaciones de modificación masiva. El módulo de productores archivísticos está basado en la Norma ISAAR (CPF), y es coordinado por el Centro de Información Documental de Archivos (CIDA), que actúa como agencia de normalización de encabezamientos de instituciones, familias y personas productoras de fondos y colecciones documentales. El módulo de Puntos de acceso está en estos momentos en fase de desarrollo para evolucionar las antiguas bases de datos de encabezamientos de indización de cara a su normalización para elaborar Tesauros especializados a partir de los encabezamientos de materias, personas, geográficos e instituciones, siendo el marco donde aplicar la Norma para la elaboración de Puntos de Acceso de los Archivos Estatales, publicada en 2010. Una vez que las bases de datos estén depuradas y preparadas, será el momento para ofrecer en los buscadores de 
PARES tesauros y registros de autoridad. El módulo de descripción en red de PARES permite a cualquier usuario del sistema la organización y la ordenación de la información de la base de datos de forma personalizada, sin que afecte a los criterios de ordenación básicos que son indicados por los responsables de descripción de cada archivo.

Para la organización del trabajo es importante reseñar que la base de datos de unidades de descripción y de signaturas es de creación y gestión exclusiva de cada archivo, mientras que las de Puntos de Acceso y de Autoridades Archivísticas son compartidas. Es decir, que mientras un registro descriptivo corresponde a una única unidad documental que está preservada en un archivo concreto, los puntos de acceso de encabezamientos y autoridades son entidades normalizables para la gestión compartida (un punto de acceso: N unidades documentales). Así, por ejemplo, un mismo encabezamiento geográfico, es decir, un topónimo, puede ser compartido por una pluralidad de unidades de descripción ubicadas en distintos archivos, y usados para identificar un lugar que aparece de forma relevante en el contenido informativo de documentos producidos en distintas épocas y sobre diferentes soportes documentales.

Este módulo de descripción contiene también una sencilla herramienta para la vinculación de imágenes a las unidades de descripción digitalizadas. Esta herramienta permite incorporar objetos digitales a las unidades de descripción previamente creadas en el sistema, de manera que los archivos puedan introducir nuevas digitalizaciones a partir, por ejemplo, de programas locales de reprografía digital, mientras que las cargas masivas de los proyectos se realizan a través del Servicio de Reproducción de Documentos de los Archivos Estatales. Esta herramienta permite también la descarga, tratamiento y gestión de las imágenes que reproducen una unidad documental concreta en formato jpg (una unidad documental: $\mathrm{N}$ imágenes). La herramienta de vinculación también permite vincular a las unidades de descripción todo tipo de ficheros y documentos electrónicos, que pueden ser publicados en Internet o ser leídos exclusivamente en Intranet. Con ella, por ejemplo, se pueden vincular a las unidades de descripción transcripciones, catálogos y documentos técnicos a las unidades de fondo y serie. $Y$ en caso de Intranet se pueden asociar documentos como, por ejemplo, copias en formato pdf de la legislación publicada en el BOE que pueda afectar a un fondo o serie, introducir tablas de equivalencias, guías de descripción, y cualquier otro documento que los técnicos de los archivos consideren oportuno.

Para la revisión de la información existe una herramienta específica, que ayuda a gestionar las bases de datos de unidades descriptivas, signaturas, autoridades archivísticas y puntos de acceso de forma diferenciada y relacionada al mismo tiempo. Funciona como un buscador de gran capacidad y a partir de los registros localizados se pueden realizar todo tipo de operaciones masivas (editar, cortar / pegar, modificación masiva, unificar, exportar, etc.) y obtener diferentes tipos de informes destinados a facilitar fundamentalmente el trabajo de revisión en red. Las operativas masivas que supongan un alto grado de rendimiento interno de la infraestructura son gestionadas aparte en un módulo de gestión específico, que se proporciona a los responsables de estas operaciones técnicas. En la gestión y control de los Puntos de Acceso y Autoridades se ha ampliado la colaboración entre la Administración de PARES y el Centro de Información Documental de Archivos (CIDA) de cara a la gestión normalizada de estos ámbitos. Cooperación que ya existía a la hora de compartir información en el nivel de la macrodescripción y en el institucional entre el Portal de Archivos Españoles y el Censo - Guía de España e Iberoamérica. El CIDA ha sido designado como centro agencia normalizadora en estas materias en el ámbito de los Archivos Estatales, actuando especialmente en la validación de encabezamientos y entidades en estos entornos de información compartida por más de un archivo.

Complementario al módulo de reprografía existe una réplica del buscador en Internet que permite a los técnicos de los archivos revisar la información en tres estados de edición en virtud de dos niveles de accesibilidad, técnica y legal:

1. Información sin restricción de acceso público: estado "Publicado" en Internet.

2. Información con restricción de acceso público: estados "Grabado" (pendiente de revisar) y "Revisado" (pendiente de publicar).

Esta herramienta permite, según el grado de responsabilidad en función de las tareas que hay que realizar, que un usuario pueda trabajar solo en el entorno de su archivo o navegar por toda la base de datos integrada. Los usuarios capacitados que accedan a toda la base de datos solo podrán realizar tareas de modificación exclusivamente en el entorno del centro al que estén vinculados. 
El módulo de gestión interna fue elaborado a partir de 2006 para proporcionar herramientas de gestión comunes para la gestión de los servicios públicos archivísticos de registro de investigadores presenciales a un archivo, de control y gestión de Salas de Investigación, así como para los servicios de reprografía. Al mismo tiempo, han sido diseñadas para permitir gestiones específicas de cada archivo a partir del modelo común. Desde 2009 se encuentra en proceso piloto en los Archivos General de Simancas y de la Real Chancillería de Valladolid, donde fue presentado a la comunidad archivística de los centros junto a investigadores profesionales. A lo largo de 2011 se hizo su puesta en funcionamiento en estos centros y comenzó el proceso de incorporación al resto de archivos. La idea central de este módulo, frente a las generaciones anteriores, es conseguir la gestión actualizada de un único expediente electrónico de investigadores presenciales, que proporcione la información necesaria sobre los documentos consultados por los mismos a lo largo de un historial, así como el número de investigadores que han accedido a cada unidad documental concreta. Esta información es muy útil para determinados procedimientos de certificación e información oficial. Las bases de datos personales tienen acceso controlado y están vinculadas a los responsables que indiquen la dirección de cada centro, garantizándose responsablemente el buen uso y gestión.

Este módulo tiene incorporadas también herramientas para el control de las referencias vía correo postal, correo electrónico distinto al "Contacte" y vía telefónica. También proporciona la gestión electrónica de algunos procesos de control de fondos, como la entrada y salida de documentos para préstamos o exposiciones externas. Es el ámbito a partir del cual seguir desarrollando las herramientas de forma escalable para cubrir toda la problemática del control y gestión físicos de los fondos documentales, teniendo en cuenta las características específicas de archivos con fondos de naturaleza administrativa o intermedia, como es el caso del Archivo General de la Administración o del Archivo Central del Ministerio de Cultura.

El diseño de la arquitectura modular de PARES permite, como hemos indicado anteriormente, la integración de la información, su gestión distribuida y la evolución escalable de un sistema cuyos contenidos en bases de datos y bancos de imágenes digitales ha tenido un crecimiento exponencial desde los ini- cios y, una vez que se han migrado la mayoría de las bases de datos externas, se prevé a medio plazo un crecimiento tal vez de menor intensidad debido al contexto socioeconómico en que estamos y también debido a la mayor dedicación a las tareas de actualización y mejora de la calidad de las descripciones.

\section{LAS REFERENCIAS VIRTUALES}

La progresiva incorporación de las tecnologías informáticas y de las comunicaciones a partir de los años ochenta al mundo de los archivos ha permitido acuñar el término "usuario virtual" de los servicios archivísticos, procedente de la tradición anglosajona (Taylor, 1984). La experiencia en el ámbito del Ministerio de Cultura nos lleva a valorar el importante y estratégico papel que han adquirido los servicios de referencias de los archivos así como de la administración de la plataforma PARES desde el momento en que la difusión en Internet permite el acceso potencial a la amplia comunidad virtual de internautas. Los primeros sistemas de información automatizados a nivel local de los años 80 y 90 ya mostraban las capacidades y la relevancia de estos servicios como uno de los elementos de calidad en virtud de la rapidez y pertinencia de las respuestas (Díez de los Ríos, 1996).

El Portal de Archivos Españoles cuenta con una serie de herramientas que permiten ofrecer un sistema de referencias mediante un doble proceso de información virtual y otro directo. Las referencias directas están representadas por la posibilidad de atención telefónica y vía correo electrónico mediante la herramienta de "Contacte". En el caso de la administración de PARES, ubicada en la Subdirección General de los Archivos Estatales, ha desaparecido prácticamente la comunicación vía correo postal o fax que, sin embargo, significativamente se continúa dando en los diferentes archivos. Las respuestas y orientaciones suelen ser inmediatas, no dilatándose generalmente más de lo necesario para recabar la información. El sistema de "Contacte" es también una herramienta integrada para toda la red de archivos, por lo que una consulta que, por ejemplo, llegue a la administración de PARES solicitando reprografía de un documento concreto de un archivo es inmediatamente remitida al archivo en cuestión, que procede a solucionar el caso, sin que el usuario tenga que volver a realizar la consulta en el micrositio web del archivo correspondiente. 
Entre las herramientas de referencias virtuales, PARES ofrece una amplia gama de canales de información. Existe enlace a una serie de espacios monográficos web, donde se presentan en un primer nivel los más consultados o de reciente publicación; mientras que en la pestaña "Monográficos" de la parte superior de la pantalla se guarda un directorio con todos los que han ido sucediéndose en el tiempo que quedan siempre disponibles para los usuarios e investigadores. En las secciones denominadas "Enlaces de interés" y "Recursos" se ofrece acceso a todo tipo de catálogos específicos o a directorios de recursos elaborados por los distintos archivos estatales. Las novedades y avisos suelen aparecer formando espacios web específicos en la parte central del portal, que complementariamente se enriquecen con las comunicaciones circuladas en la "Lista de distribución" de PARES a toda la comunidad de usuarios registrados en la misma. Desde el membrete del Ministerio de Cultura el usuario puede continuar su navegación por toda la web del mismo, donde se puede acceder a todo tipo de recursos de información cultural. Existe un manual audiovisual descargable en la opción "Ver video de presentación". Esta herramienta audiovisual se visualiza en el entorno denominado "CANAL del Ministerio de Cultura" como espacio de comunicación cultural específico en el entorno YouTube (http:// www.youtube.com). Aquí el usuario puede conectarse también a diferentes vídeos monográficos o reportajes de naturaleza archivística como los de los archivos General de Indias, de la Corona de Aragón, o al General de Simancas, el documental sobre el seIlo en la Administración, el vídeo sobre la obtención de copias de documentos de la "Causa General", entre otros. Y desde el "Inventario Dinámico", una vez seleccionado un archivo concreto se puede acceder directamente al micrositio web de ese centro.

Complementariamente, tanto los "Buscadores" como el "Inventario dinámico" cuentan con manuales descargables en formato pdf que informan detalladamente sobre el funcionamiento de las herramientas, así como sobre las estrategias de búsqueda y navegación.

Hasta el momento no se ha ofrecido en PARES un espacio para la información estadística, debido a la atribución de comunicación de estos datos el propio Ministerio de Cultura, que la ofrece en un apartado específico de "Servicios al ciudadano" localizado en el primer nivel de la web del Ministerio y de la Subdirección General de los Archivos Estatales, que es enlazable desde el membrete institucional de PARES. Para las próximas versiones de PARES se incorporará ya una herramienta de información general estadística a partir de los datos publicados.

Desde enero de 2012, los internautas pueden acceder a un proyecto piloto de comunidad en redes sociales, denominado "Portal de Archivos Españoles: PARES", disponible en Facebook ${ }^{20}$. Este espacio colaborativo sí exige el previo registro del cliente en la comunidad, acto que a cambio le permite, además de leer la información, participar con comentarios y propuestas, así como conocer a otros participantes interesados en la misma comunidad de intereses. El Facebook de PARES permite una interesante labor de referencias virtuales complementaria a la llevada a cabo por el contacte, la lista de distribución, el teléfono o la visita presencial en la sede de los Archivos Estatales o de cualquiera de los archivos de la red. La tecnología de esta red social permite al usuario también compartir los contenidos, al mismo tiempo que a nuestro portal le permite elaborar comunicaciones breves que enlazan a direcciones URL, cargando imágenes digitales o vinculando ficheros textuales. Ello permite dar relevancia periódica a todo tipo de noticias de prensa destacadas o de noticias culturales que previamente estén disponibles en web. Es el marco ideal para replicar la información, como por ejemplo de avisos de jornadas, cursos o actividades, tanto en PARES como en las sedes de nuestros archivos.

Aunque las herramientas de PARES se diseñaron a partir de las carencias de las generaciones anteriores y especialmente a partir de propuestas directas de los usuarios, tanto las herramientas de acceso y navegación como las referencias virtuales adolecen aún de determinados elementos (García y Chain, 2010), que serán necesariamente abordados en las próximas versiones de PARES, en un necesario acercamiento a la filosofía de la web 2.0 y la web semántica. A pesar de esas carencias, menores pero significativas, PARES se ha convertido en un modelo en la evolución de los archivos del siglo XIX a los del siglo XIX por su eficacia operativa para acercar los archivos históricos a los ciudadanos, rompiendo las barreras tradicionales del acceso presencial y ayudando a la creación de modelos operativos en el acceso y la transmisión del conocimiento (Parra 
et al., 2010). No obstante, los retos siguen siendo importantes, especialmente de cara a alcanzar las metas de la denominada web semántica.

A pesar de que nuestro portal aún presenta un bajo nivel de interactividad, tiene una amplia audiencia formada por estudiantes, profesores y lo que se viene denominando el colectivo de "autores" entre una amplia gama de ciudadanos. PARES proporciona un aceptable grado de operatividad, como se demuestra con el uso y referencia de PARES en la elaboración de herramientas e instrumentos de información virtuales. En 2010, especialistas del ámbito del $\mathrm{I}+\mathrm{D}+\mathrm{i}$ universitario español usaron $P A-$ $R E S$ para ensayar una guía informativa del acceso a los fondos del Archivo General de Indias a través de nuestra plataforma (García y Mas, 2010). Un año antes, el mismo equipo había experimentado un modelo de evaluación o auditoría a través del análisis de la web de los archivos históricos estatales del Ministerio de Cultura (García y Chain, 2009). Esta línea de auditoría fue ampliada en 2010 al Portal de Archivos Españoles, que presenta la enorme virtud de ofrecernos un feedback externo sobre la funcionalidad y percepción de nuestra plataforma (García y Chain, 2010). Además del valor intrínseco de la documentación archivística digitalizada que se ofrece en Internet, sus progresivos logros están también relacionados con la organización del trabajo interno de los profesionales de los archivos y las herramientas internas que necesitan para su trabajo. Todo ello en su conjunto propicia la labor de preservación, tratamiento, descripción gestión y difusión de nuestro patrimonio documental; esfuerzos que se ven reflejados cuando el Portal de Archivos Españoles es localizable en repositorios internacionales como el European History Primay Source, integrado en la www Virtual Library History ${ }^{21}$.

PARES se ha constituido en un espacio donde el término anglosajón "usuario" adquiere una rica polisemia (Taylor, 1984), por la que el investigador profesional o aficionado, junto al ciudadano que busca antecedentes administrativos o jurídicos o la persona que busca recursos de información para la enseñanza o el autoaprendizaje se igualan ante las mismas problemáticas que plantea el acceso y la navegación por una plataforma de información cultural de naturaleza archivística. Todos estos clientes, independientemente del uso y finalidad que persigan, se enfrentan a los mismos retos consistentes en la simultánea necesidad de conocer: ¿cómo buscar e indagar?, ¿qué existe?, ¿qué novedades existen dentro de la masa de información fácilmente reconocibles?, ¿cómo guardar y recuperar de forma fácil la memoria de la propia investigación? Y, sobre todo, necesitan conocer cómo solventar de forma rápida y eficiente cualquier duda en cualquier momento. Por ello, las problemáticas del acceso y la accesibilidad deben estar relacionadas con uno de los objetivos fundamentales del profesional de los archivos, proporcionar información archivística de la mayor calidad posible, caracterizada por los conceptos de fiabilidad, seguridad, integridad, accesibilidad y estabilidad posibles (Sánchez Mairena, 2011).

Desde muy pronto, la experiencia de trabajo en PARES ha inspirado también a los propios archiveros a contextualizar el trabajo de sus centros en el ámbito del trabajo de la organización de los Archivos Estatales y con su marco de referencia en nuestra plataforma. En el IV Congreso de la Lengua española, la directora del Archivo General de Indias valoró en la perspectiva de las fases de informatización de los Archivos Estatales la relevancia internacional conseguida por ese archivo a partir de la difusión digital de los documentos en Internet (Simó, 2007). $Y$ recientemente se ha tratado sobre la representación de la información de un archivo en PARES en función del modelo de los cuadros de clasificación como reflejo de una de las preferencias tradicionales de la investigación especializada (Álvarez y Coca, 2011). PARES es valorado como recurso de información científica en Internet, catalogado como una "referencia útil" (Gutiérrez y Molero, 2011), convirtiéndose ya en un hito en diferentes publicaciones de referencias científicas (Pons, 2008). No obstante, la naturaleza archivística del Portal de Archivos Españoles a veces no es tenida en cuenta por los propios profesionales de la información documental, en el momento en que se alude a PARES como un recurso más dentro del concepto de biblioteca digital (Méndez, 2009, pp. 40-41), a pesar de que desde el punto de vista de la epistemología científica esto puede suponer una grave distorsión metodológica y conceptual; que desafortunadamente se expande, cuando observamos que en importantes recursos de información cultural como el directorio de la Biblioteca Nacional de España (www.bne.es), nuestro portal forma parte a su vez del directorio de "Colecciones digitales españolas", antes que del de "Recursos digitales", diluyéndose impropiamen- 
te la naturaleza archivística frente al concepto de colección, ajeno al Principio de Procedencia como eje fundamental de la metodología archivística ${ }^{22}$. Es corriente comprobar cómo en los servicios bibliotecarios existen colecciones de manuscritos que en gran medida son de naturaleza y procedencia archivística, pero el tratamiento documental proporcionado no es plenamente archivístico, con el riesgo de pérdida del vínculo y del contexto archivísticos en los sistemas de información y referencias que se generen. Esta línea prolifera debido al atractivo y las facilidades de las nuevas tecnologías de la información y las comunicaciones (TIC), donde un reciente "neo nominalismo" apuntala a la propia epistemología de las ciencias del documento, dado que las antiguas fuentes documentales ahora son consideradas como "fuentes digitales" bajo el único denominador común de su acceso en Internet (Benito y García, 2008). Y creemos que esta línea puede suponer un grave riesgo de desvirtuación del documento archivístico como uno de los productos de nuestra secular historia de la cultura escrita. El documento archivístico puede tener diferentes usos, funciones y representaciones, unos analógicos (el documento, el códice, el mapa, la fotografía, etc.) y otros equivalentes virtuales, como la representación de los primeros mediante la unión de un formulario normalizado estructurado al que se vinculan facsímiles digitales. Pero la representación y el uso electrónico del documento preexistente no tienen por qué crear nuevas entidades documentales de naturaleza digital, sino que en realidad vienen a representarlas mediante otro soporte $u$ otra dimensión de preservación y gestión. Es decir, que el documento, independientemente de que nazca bajo un soporte tradicional o electrónico, adquiere su naturaleza documental en virtud de múltiples variables.

\section{LA PRESERVACIÓN Y LA DIFUSIÓN DE LA MEMORIA ESCRITA ARCHIVÍSTICA: EL PLAN DE DIGITALIZACIÓN Y CONSULTA EN RED DE LOS ARCHIVOS NACIONALES}

El Portal de Archivos Estatales (PARES) así como los sistemas de información precedentes se han nutrido de bases de datos descriptivas que se crean en las propias herramientas electrónicas o procedentes de migraciones de bases de datos externas. A estas bases de datos documentales en un momento posterior se vinculan los diferentes proyectos de reproducción digital de los documentos previamente descritos.
En el año 2006 la Subdirección General de los Archivos Estatales impulsó el Programa de Descripción Intensivo de los Archivos Estatales (PIDA), que entre esa fecha y 2010 ha producido una media de un millón de registros para su difusión en PARES. En un primer lugar, se destinó a informatizar instrumentos de descripción no integrados en las fases anteriores, así como a la migración de todas las bases de datos locales. En el año 2009, comenzó a plantear la problemática de la calidad de las descripciones que había que difundir en nuestro portal, conforme a los criterios de calidad y conformidad a las normas archivísticas, coincidiendo con la aparición del Modelo Conceptual del Sistema Archivístico Español, elaborado por la CNEDA (Comisión Española de Normas de Descripción Archivística), y el impulso de la primera norma para la elaboración de Puntos de Acceso de los Archivos Estatales.

En 2008, a la vista de los resultados conseguidos en el Portal de Archivos Españoles, la entonces Dirección General del Libro, Archivos y Bibliotecas diseñó el Plan de Digitalización y Consulta en red de los Archivos Estatales, aprobado en Consejo de Ministros del 16 de junio de ese año. El plan se marcaba como ejes de intervención la normalización, la preservación, la difusión y la creación de infraestructuras adecuadas. Para ello, se estructuraba en nueve líneas de actuación, parte de ellas directamente relacionadas con PARES:

1. Programa General de Digitalización, para vincular a las bases de datos descriptivas previamente elaboradas.

2. Programa Intensivo de Descripción, para sustentar la línea anterior.

3. Potenciar el Portal de Archivos Españoles (PA$R E S)$ como tecnología archivística.

4. Ampliación del Programa de Ayudas a Proyectos Archivísticos de instituciones privadas sin ánimo de lucro.

Estos programas se unen a los proyectos propios de cada centro en su propia dinámica de trabajo. Entre mayo de 2007 y diciembre de 2012, el Portal de Archivos Españoles ha experimentado un aumento de los contenidos archivísticos que gestiona y difunde, que se muestran perfectamente en la siguiente tabla y gráfico de indicadores generales: 
Tabla III

\begin{tabular}{|l|c|c|c|c|}
\hline & Unidades descriptivas & Imágenes & Autoridades & Puntos de Acceso \\
\hline $\mathbf{2 0 0 7}$ & 1.944 .413 & 12.983 .859 & 27.974 & 1.026 .054 \\
\hline $\mathbf{2 0 0 8}$ & 2.622 .973 & 13.560 .312 & 28.152 & 1.98 .325 \\
\hline $\mathbf{2 0 0 9}$ & 4.692 .611 & 17.477 .619 & 29.425 & 1.133 .937 \\
\hline $\mathbf{2 0 1 0}$ & 5.018 .347 & 24.321 .225 & 30.773 & 1.195 .844 \\
\hline $\mathbf{2 0 1 1}$ & 5.437 .362 & 27.141 .358 & 24.017 & 1.147 .049 \\
\hline $\mathbf{2 0 1 2}$ & 5.677 .189 & 30.653 .521 & 28.341 & 1.268 .580 \\
\hline
\end{tabular}

Gráfico 1

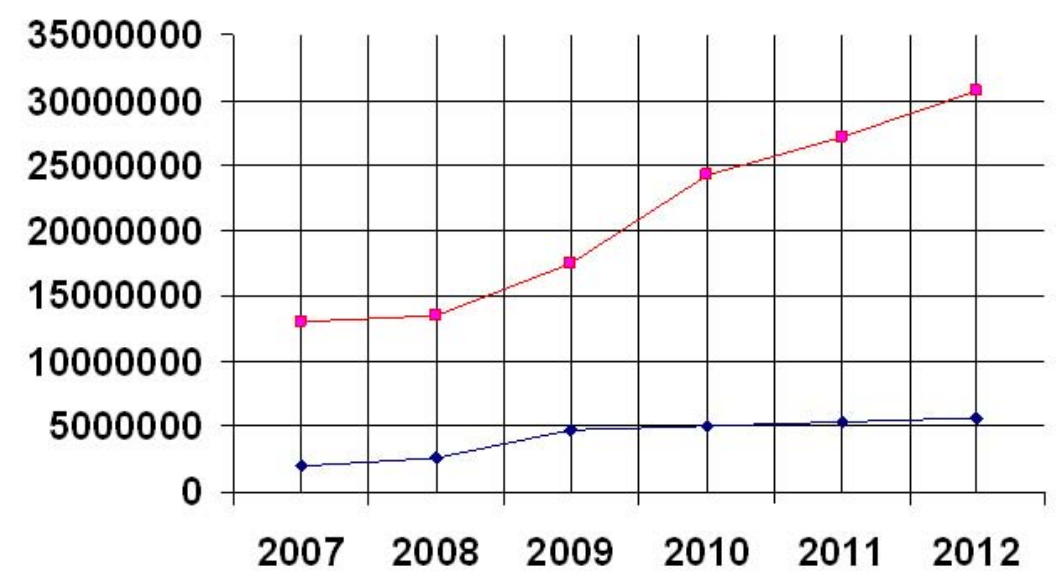

\section{- Descripciones - - Imágenes}

\section{LOS MICROSITIOS WEB ARCHIVÍSTICOS ESPECIALIZADOS}

Dentro del Portal de Archivos Españoles se difunden diferentes micrositios de naturaleza archivística. Una parte de ellos fueron iniciados en etapas anteriores y otros han sido creados en PARES. Sus datos pueden proceder de fuera del sistema de información de PARES y en otros casos desarrollarse a partir del mismo (Sánchez, 2008, pp. 128-129).

El monográfico sobre la Guerra de la Independencia española (1808-1812) ha sido desarrollado por el Archivo Histórico Nacional como una exposición virtual que se nutre de documentos conforme van siendo descritos y publicados en PARES a partir de sus series y fondos de procedencia en ese archivo. La clave consiste en utilizar un punto de acceso de materias común a todos los registros que pasan automáticamente a difundirse, además de en PARES, en este micrositio especializado, donde la base de datos archivística in- teropera con otros recursos de información. Este espacio se ha convertido en una verdadera unidad documental sobre el tema, utilizando los facsímiles de los documentos protagonistas de los acontecimientos.

El Portal de Víctimas de la Guerra Civil integra descripciones analíticas de personas que aparecen en documentos preservados en archivos de titularidad estatal, tanto de gestión directa por el Ministerio de Cultura, como transferida, caso del Archivo Histórico Provincial de Aragón. En este micrositio destaca el recurso al video para orientar a los ciudadanos en la forma de navegar y obtener copias y certificaciones de los documentos localizados para el ejercicio de derechos civiles o para la investigación. Este vídeo se localiza también en el Canal Cultura dentro de YouTube.

El Portal de Movimientos Migratorios Iberoamericanos es un espacio colaborativo sobre este tema entre archivos españoles e iberoamericanos con documentación relativa a los procesos migratorios. Su principal 
característica es la incorporación del multilingüismo en la navegación extendido a las lenguas cooficiales de España y al inglés, además de aplicarse ya la normalización de los Puntos de Acceso de personas y geográficos en el motor de búsqueda.

Estos monográficos son espacios donde se pueden adaptar diferentes tecnologías web, caso del Archivo General de la Administración con las Danzas de España, que incluye documentos audiovisuales digitales, o el Catálogo Monumental de España en Google Earth, donde se aplica la metodología de la geo-referenciación.

En estos momentos, se está desarrollando el próximo Portal de Archivos Privados, un espacio donde se difundirán también de forma integrada las bases de datos producidas en el programa de ayudas económicas a proyectos archivísticos sin ánimo de lucro de la Dirección General del Libro, Archivos y Bibliotecas a instituciones privadas.

Los monográficos consultables actualmente en PA$R E S$ son los siguientes ${ }^{23}$ :

\section{LA TRANSFORMACIÓN DE PARES EN UN SISTEMA DE ARCHIVOS ABIERTOS}

En el Report on archives (Report, 2005, pp. 81-107) se planteaba la preparación de un Portal en Internet de archivos y documentos que a partir de 2007 se denominó APENet [www.apenet.eu] que desde 2013 ha pasado a denominarse APEx [http://www.apex-project. eu/]. El Portal estará hospedado en la infraestructura de uno de los Archivos estatales o nacionales de un país miembro de la UE, en colaboración con el resto de los servicios archivísticos de los otros estados miembros e instituciones europeas. Esto significa que los archivos a escala europea tendrán su propia visibilidad social unificada, independientemente de que el portal europeo será el proveedor de contenidos culturales archivísticos a EUROPEANA [www.europeana.org], el "mega" portal cultural. Con el tiempo, el portal de archivos irá integrando todas las iniciativas archivísticas locales, privadas o regionales que en estos momentos estén contribuyendo a diferentes recolectores, caso de España respecto a HISPANA [http://hispana.mcu.es], que es el directorio y

Tabla IV

\begin{tabular}{|l|c|c|}
\hline Micrositio difundidos en PARES & Registros & Imágenes \\
\hline 1. Portal de Movimientos Migratorios Iberoamericanos & 74.948 & 238.444 \\
\hline 2. Portal de Víctimas de la Guerra Civil y de represaliados del Franquismo & 991.488 & 0 \\
\hline $\begin{array}{l}\text { 3. Archivo Fotográfico de la Delegación de Propaganda de Madrid } \\
\text { durante la Guerra Civil }\end{array}$ & 3.048 & 6.095 \\
\hline 4. Respuestas Generales del Catastro del Marqués de Ensenada & 13.118 & 300.818 \\
\hline 5. Españoles deportados a campos nazis & 8.707 & 0 \\
\hline 6. Guerra de la Independencia & 12.038 & 341.094 \\
\hline 7. Carteles de la Guerra Civil & 2.293 & 2.310 \\
\hline 8. Portal del Bicentenario de las Independencias Iberoamericanas & 7.500 & 991 \\
\hline \multicolumn{1}{|c|}{ Subtotal } & 1.111 .277 & 889.767 \\
\hline Micrositios difundidos en la Web de Archivos (enlazables desde PARES) & & 0 \\
\hline 9. Guía de Fuentes Documentales (CIDA) & 202.501 & 113.621 \\
\hline 10. Legislación Española (RAH - MCU) & 35.355 & 0 \\
\hline $\begin{array}{l}\text { 11. Militares y miembros de las Fuerzas de Orden Público al servicio de } \\
\text { la II República (CDMH) }\end{array}$ & 350.289 & $\mathbf{1 2 5 . 3 5 8}$ \\
\hline $\begin{array}{l}\text { 12. Muertos y desaparecidos del Ejército de Tierra de la República } \\
\text { (CDMH) }\end{array}$ & 59.852 & 1.015 .125 \\
\hline 13. Catálogo de Mapas, Planos y Dibujos en los Archivos Estatales (CIDA) & 7.632 & 7.632 \\
\hline 14. Danzas de España (AGA) & 234 & 234 \\
\hline 14. Catálogo Monumental de España en Google Earth & 6.871 & 3.871 \\
\hline Total & 1.771 .011 & \\
\hline
\end{tabular}

*Objetos digitales: grabaciones audiovisuales. 
recolector de recursos digitales del Ministerio de Educación, Cultura y Deporte de España, y donde a través de los recolectores bibliotecarios están contribuyendo determinados archivos municipales, fundamentalmente. Este recolector integra en estos momentos 2,5 millones de objetos digitales procedentes de 131 repositorios locales distintos.

El Portal de Archivos Españoles a finales de 2010 integra, como hemos dicho, unos 5 millones de registros descriptivos en formato ISAD (G) que tienen vinculadas unos 23,4 millones de imágenes digitales. El portal español tiene previsto ser uno de los principales proveedores de contenidos cuando se inaugure $A P E x$, junto con Alemania y Finlandia. En este sentido, la interoperabilidad con los grandes proyectos de difusión europeos ha incidido en la necesidad de evolucionar PARES desde un sistema de archivos anclado en el estilo de la web 1.0 hacia el sistema de Archivos Abiertos. Para ello, en 2010 se ha iniciado la transformación, según la filosofía de la Open Archives Initiative - Protocole for Metadata Harvesting [http://www.openarchives.org], de la plataforma en PARES-OAI. Para ello, la arquitectura basada en la ecuación de información centralizada y gestión distribuida ha sido un paso estratégico. La centralización de la infraestructura tecnológica simultáneamente a la gestión diferenciada en cada archivo se ha realizado integrando a su vez tres procesos simultáneos: 1) Las herramientas de PARES están optimizadas para usos archivísticos y para fines de consulta e investigación; 2) La normalización en la creación y gestión de la información conforme a las Normas vigentes; 3) La especialización de las aplicaciones, permitiendo la gestión diferenciada tanto de los servicios archivísticos como de los diferentes fondos documentales en virtud de perfiles y capacidades diferenciadas. La clave está en la integración normalizada de la información, que es un elemento de coordinación que permite los procesos de contribución de contenidos archivísticos a APEX y otros repositorios OAI posibles. La adaptación de PARES a las distintas normas archivísticas (Puntos de Acceso, familia de normas del ICA) $C I A)$ mediante un sistema integrado es lo que posibilita la implantación del trabajo normalizado al mismo tiempo que permite la contribución de contenidos a los grandes repositorios internacionales.

PARES se desarrolló inicialmente en la línea de la incorporación de los estándares del Consejo Internacional de Archivos. Para la descripción de los documentos se utiliza la norma ISAD (G), con una evolución de los campos principales según el modelo de descrip- ción de los Archivos Estatales elaborado entre 1995 y 2002, que se incorporó en primer lugar a $A E R$. Este modelo de datos estaba enriquecido con determinados metadatos técnicos para la descripción de materiales especiales como cartografía y fotografía, según las experiencias descriptivas llevadas a cabo en los Archivos Estatales (Sánchez, 2008). Además, conforme la práctica de trabajo lo ha propiciado, se han elaborado diferentes metadatos de auditoría, difusión, descripción y control. No obstante, estas iniciativas se han llevado a cabo para dar operatividad al trabajo de descripción, dado que hasta la fecha no contamos con un modelo de normas nacionales de descripción definitivo. De hecho, la Comisión de Normas Españolas de Descripción Archivística (CNEDA) no comenzó a funcionar como Comisión Ministerial hasta el año $2007^{24}$, y en estos momentos se ha publicado el modelo conceptual del sistema de información archivística, mientras que está pendiente aún el modelo formal. A partir del modelo conceptual, PARES debe ser el espacio en el que realizar determinadas adaptaciones en la lógica de relaciones entre los niveles de descripción superando los corsés del esquema rígidamente jerarquizado de niveles descriptivos de la tradición archivística española, influida por una enorme carga administrativista y de tradiciones en las que se fundían las lógicas de la unidad archivística (el documento) con la de la unidad de conservación (la caja, el legajo, la carpeta), así como de otras dinámicas de naturaleza clasificatoria del conocimiento para agrupar e identificar los diferentes fondos y colecciones. Respecto a la arquitectura relacional, el diseño originario de PARES, basado en una arquitectura de bases de datos relacionales, se adapta al esquema conceptual de CNEDA, permitiendo básicamente la evolución del sistema de información para agregar diferentes estándares o estructuras de metadatos cuyas relaciones enriquecen al documento según las nuevas propuestas descriptivas (Delgado, 2007).

En 2009 se comenzó la incorporación de un módulo de elaboración y gestión de Autoridades según la norma ISAAR - CPF, estando previsto en el organigrama de la Subdirección General de Archivos que la supervisión y normalización final de este ámbito de trabajo esté a cargo del Centro de Información Documental de Archivos [CIDA]. La descripción de las instituciones productoras de Archivos según la nueva norma ISDIAH la debe proporcionar el Censo - Guía de Archivos de España e lberoamérica.

Para proveer de contenidos desde PARES a APEX se han comenzado a incorporar las pasarelas [cross- 
walk] que permitan el flujo de metadatos con información archivística según el lenguaje de marcado. En un primer momento, se ha elaborado una pasarela entre ISAD (G) de PARES y XML-EAD, en un segundo momento se han hecho las mismas pruebas de carga entre ISAD (G) de PARES con el XML-EAD elaborado específicamente por APEx, todo esto en cuanto a los contenidos archivísticos, es decir, las entidades documentales físicas (documentos) y las entidades documentales intelectuales (unidades de fondo, colección y serie). La interoperabilidad de los Productores y de las Instituciones archivísticas se hará con sendas pasarelas entre ISAAR-CPF de PARES con XML-EAC-CPF y mediante la pasarela de ISDIAH del Censo-Guía con $X M L-E A G$, respectivamente. Una vez asentados estos estándares y maduradas las estrategias de trabajo en los archivos, se procederá a la incorporación de las normas sobre Funciones (ISDF), ámbito en el que aún no está consensuado el nuevo estándar o formato de intercambio (Fox, 2008).

Como podemos observar, la arquitectura de estos flujos consistirá en una exportación de $X M L$ basados en $E A D$ y sus formatos complementarios a partir de la "Familia de normas del CIA" (ISAD, ISAAR, ISDI$A H)$ desde PARES - Censo-Guía hacia el repositorio $O A /$ del Ministerio de Cultura [OAI-MCU], que actúa como proveedor de servicios (Barrueco y Subirats, 2003, pp. 96-106; Peset y Ferrer, 2008). A partir de esta tecnología se proveerá de contenidos archivísticos directamente a APEx mediante el formato Dublín Core. A su vez, el portal de archivos europeo proveerá contenidos archivísticos a EUROPEANA utilizando el formato Dublín Core avanzado [ESE: Europeana Semantic Elements]. Además de estos flujos de información, los Archivos Estatales pueden proveer también información archivística a través de HISPANA [http:// roai.mcu.es/es/inicio/inicio.cmd] en aquellos casos de documentos que puedan ser susceptibles de analizarse simultáneamente en formatos archivísticos como ISAD (G) o bibliotecarios como ISBN, MARC. Esto se está realizando con documentos con formatos especiales como, por ejemplo, la rica colección de Mapas, Planos y Dibujos del Archivo General de Simancas (Simancas, Valladolid), que se ha integrado primero en el Catálogo colectivo de la Red de Bibliotecas de los Archivos Estatales del CIDA; y en otro momento se incorporará la importante colección de Prensa Histórica del Centro Documental de la Memoria Histórica (Salamanca). Una vez finalizado este proceso de adaptación de PARES en un repositorio OAI, se deberá elaborar un protocolo de flujos de información y cooperación con otros sistemas de información archivísticos de España para propiciar su integración en APENet / EUROPEANA a partir de la infraestructura $O A l$ archivística del Ministerio de Cultura. En este sentido, en 2006 comenzó una nueva línea de fomento de las ayudas a proyectos archivísticos sin ánimo de lucro de instituciones privadas de nuestro país. Las instituciones beneficiarias se comprometían a trabajar normalizadamente según el estándar archivístico de $I S A D(G)$ para propiciar la migración de una copia de los datos en PARES-OAI. Para ello, dentro del Portal de Archivos Españoles se está elaborando un micrositio específico para estos Archivos Privados, y a partir de aquí cualquier institución que provea datos archivísticos de sus fondos tendrá una posibilidad de estar presente en $A P E x$, aumentando su visibilidad social, además de la ya proporcionada por el CensoGuía y por PARES. El mantenimiento y la gestión de estas plataformas archivísticas abiertas se hacen por parte del Ministerio de Cultura, buscando siempre la aportación constante de contenidos culturales de calidad en el entorno de Internet.

Los metadatos interoperables serán definidos por $A P E x$, suponiéndose que serán todos o parte de los campos obligatorios de ISAD (G): Archivo, Título, Signatura, Nivel descriptivo, Soporte y Volumen, y Registro de autoridad, a los que se unirán hipervínculos a la unidad descriptiva completa en el sistema de información de origen, en nuestro caso PARES, a los objetos digitales y a cualquier elemento vinculado que se estime.

Una vez estabilizada la nueva plataforma PARES$O A l$, el siguiente paso será la creación de la fase de recolector de contenidos archivísticos proporcionados por otros sistemas y redes archivísticas. Ante ello, PARES-OAl se aviene como un excelente ámbito para la creación de marcos de cooperación archivística mediante el establecimiento de protocolos de trabajo, al mismo tiempo que potencia de cara al exterior la normalización archivística.

\section{RETOS DE PARES: LA MEJORA DEL ACCESO... HACIA LA WEB 2.0}

Los retos que se plantean a PARES son un reflejo de los que tiene la profesión archivística. Desde el punto de vista de la "alfabetización informacional", o grado de eficiencia en el uso de los buscadores archivísticos, existe una amplia mediatización, tanto tecnológica como en formación archivística, a la que se enfrenta la comunidad de usuarios, compuesta tanto por investigadores académicos, como por ciudadanos que buscan antecedentes o información para su formación. Los investigadores profesionales o aficionados acaban 
Tabla V. Protocolo Transmisión Contenidos PARES OAI - APENet / EUROPEANA

\begin{tabular}{|c|c|c|c|c|}
\hline $\begin{array}{c}\text { Proveedor de } \\
\text { Datos }\end{array}$ & Metadatos & Proveedor servicios & Protocolo & Servicio \\
\hline PARES & $\begin{array}{l}\text { ISAD }(G) \text { - EAD } \\
\text { ISAAR-CPF -EAC }\end{array}$ & \multirow{3}{*}{ OAI-MCU } & EAD APEnet & APENet \\
\hline CENSO-GUÍA & ISDIAH - EAG & & Dublin Core & HISPANA \\
\hline HISPANA & & & Duiblin Core ESE & \multirow{2}{*}{ EUROPEANA } \\
\hline APENet & & OAI-APEnet & Dublin Core ESE & \\
\hline
\end{tabular}

enfrentándose a los mismos retos: cómo buscar, qué información está disponible, qué novedades hay en el conjunto de la masa de información, cómo guardar y gestionar la "memoria personalizada" de las búsquedas y cómo solventar las dudas (Sánchez, 2011).

En estos momentos se está preparando el diseño de la Plataforma para adaptarse a las soluciones que debe aportar la web semántica y la adaptación a la filosofía de la web 2.0. La búsqueda de métodos para que el cliente de las herramientas archivísticas trabaje y navegue con facilidad necesitará a su vez de un buen nivel de calidad y parametrización de la información descriptiva de los documentos, es decir, de un buen análisis documental, por el cual las entidades documentales archivísticas primen sobre las tradicionales entidades de preservación, como la caja, el legajo o la carpeta.

Por otro lado, la incorporación del concepto de bidireccionalidad de la información, mediante la participación activa del cliente en las plataformas archivísticas web como PARES consistiría básicamente en la adopción de herramientas colaborativas tipo wiki; y el proporcionar información disponible en redes sociales para que los usuarios conozcan las novedades y poder usar los contenidos archivísticos difundidos. Todo ello implica la transformación gradual en diseño y en arquitectura del Portal de Archivos Españoles hasta convertirse en un verdadero canal de comunicación, siempre dentro de los protocolos de accesibilidad y difusión de la web del Ministerio de Cultura.

Junto a esta evolución que imponen los rápidos avances tecnológicos, aplicada al mundo de la co- municación y la difusión en Internet, surgen nuevos retos. El acceso on line ha ayudado en la última década a acercar los archivos a la ciudadanía, al mismo tiempo que se rompían las tradicionales barreras en el acceso presencial (Sánchez, 2008). Pero surgen dos nuevos y complejos retos: por un lado, la obsolescencia de los facsímiles digitales de los documentos analógicos, por lo que las nuevas generaciones de alfabetizados digitales en el día de mañana probablemente no puedan leer los viejos documentos manuscritos en cualquiera de los sistemas escriturarios; por otro lado, asumir irreflexivamente la moda de aplicar la filosofía web 2.0 puede plantear problemas de largo alcance que es necesario que las organizaciones públicas valoren detenidamente.

El nuevo concepto de referencias virtuales las veinticuatro horas del día solo puede ser mantenido con una plantilla permanente y numerosa de profesionales. Y la vasta red de herramientas y de recursos colaborativos en Internet necesita también de una constante plantilla de profesionales que lean, revisen y controlen la pertinencia de los comentarios. Como alguien ha expuesto ya, las redes sociales sin control de la pertinencia de la información intercambiada, que no implica ningún planteamiento censor, necesitan de una vigilancia constante debido a la posibilidad de difusión de contenidos basura e ilegales que las redes sociales vinculadas a instituciones y servicios públicos no pueden dejar de controlar para la eficiente consecución de sus fines.

Finalmente, no queremos acabar sin recordar el valor del personal técnico de los archivos, pues garanti- 
zar tanto su presencia suficiente como su formación y reciclaje es fundamental y estratégico en cualquier proceso de perfeccionamiento e incorporación de las nuevas tecnologías. Hay que cuidar el reciclaje tecnológico de las plantillas, así como potenciar y garantizar la transmisión del conocimiento técnico y experto en los fondos documentales del pasado, puesto que en un futuro no podemos permitirnos que una tecnocracia perfeccionada en las últimas generaciones tecnológicas aplicadas a los archivos olvide los conocimientos necesarios para resolver problemas técnicos, jurídicos o administrativos que necesiten de un profundo conocimiento en los documentos, independientemente de sus formatos y caracteres internos.
1 El funcionamiento de PARES es posible gracias al trabajo colaborativo entre los técnicos de los Archivos Estatales gestionados por el Ministerio de Cultura, los del Área de Desarrollos Culturales de Archivos de la Subdirección General de Tecnologías y Sistemas de Información y, muy especialmente, por la dedicación del equipo del Área de Relaciones Institucionales que atiende y asiste diariamente las necesidades del Portal de Archivos Españoles, tanto las personas que han trabajado desde 2006, como las que están ahora: Aranzazu Lafuente, Cristina Díaz Martínez, Jesús Espinosa Romero y Santiago Muriel Hernández.

2 A través de la Dirección General del Libro, Archivos y Bibliotecas, cuyas líneas programáticas en materia archivística son llevadas a cabo por la Subdirección General de los Archivos Estatales.

3 El proyecto fue fruto de la firma de un convenio entre el Ministerio de Cultura, IBM España y la Fundación Ramón Areces. El sistema se instaló en pruebas en 1991 y fue inaugurado oficialmente en 1992, año que este proyecto archivístico fue reconocido con el galardón europeo Erasmus.

4 Disponible en red: http://www.mcu.es/archivos/docs/isad.pdf (acceso 13/06/2011).

5 Esta tarjeta fue establecida en el Real Decreto 1969/1999 y desapareció con el Real Decreto 1266/2006

6 http://www.apex-project.eu/

7 http://www.europeana.eu/

8 http://www.monasterium.net/
9 http://pares.mcu.es

10 http://www.mecd.gob.es/portada-mecd/, formando parte de los "Portales de interés".

11 http://www.mcu.es/archivos/index.html

12 http://www.mcu.es/archivos/CE/ArchivosCentros.html

13 A día de hoy faltan por integrarse los Archivos Centrales de las Secretarías de Estado de Educación y de Cultura.

14 Siguiendo con el ejemplo anterior, será más útil añadir elementos calificadores al término: por ejemplo, Madrid hospital; Madrid comercio, etc.; las estrategias se pueden enriquecer y ganar en precisión si aplicamos filtros por rangos de fechas, por archivos o por fondos dentro de estos. El mayor nivel de acotamiento es de momento uno de los mejores métodos para interrogar bases de datos nutrida por millones de registros como es el caso de PARES.

15 Información sobre los Niveles de descripción se proporciona en el manual de Ayuda del "Inventario dinámico", p. 8, accesible en: http://pares.mcu.es/ParesBusquedas/ PARES_Inventario_Dinamico.pdf

16 Esta extensa jerarquía existente en PARES procede de la tradición descriptiva, heredada de los sistemas de información previos y método aún vigente en la descripción de nuestra red de archivos.

17 Este es un campo de la Norma ISAD (G) que en el caso de los Archivos Estatales consta de tres elementos: A) Identificación del archivo (Acrónimo ISO de España + Código INE de la población donde radique el archivo + Acrónimo del mismo) y lo proporciona el Censo Guía de Archivos a través del Centro de Información Documental de Archivos (CIDA). B) Contexto de la unidad documental en el cuadro de clasificación del archivo según los niveles de descripción. C) Identificación de la unidad documental mediante su signatura; este elemento no aparece obviamente en las unidades de Fondo, Serie y Colección y sus divisiones.

18 Estos campos son: Archivo, Código de Referencia, Nivel descriptivo, Título, Fecha, Productor archivístico y SoporteVolumen.

19 La primera es exclusiva de PARES y la segunda fue heredada de AER y perfeccionada.

20 http://www.facebook.com/pages/ Portal-de-Archivos-Espa\%C3\%B1olesPARES/205041349525822.

21 http://primary-sources.eui.eu/ website/pares-portal-de-archivosespa\%C3\%B1oles

22 Véase los conceptos de Fondo, Serie, Colección y unidad documental en el Diccionario de Terminología Archivística: http://www.mcu.es/archivos/MC/ DTA/Portada.html.

23 Datos al 31/12/2012.

24 http://www.mcu.es/archivos/MC/CNEDA/Presentacion.html. En este espacio se ofrecen todos los documentos elaborados en el desarrollo de los trabajos. 
Álvarez-Coca González, M.a J. (2010). “La investigación histórica y los archivos en Internet. La presencia del Archivo Histórico Nacional en el Portal de Archivos Españoles (PARES)". Cuadernos de Historia Moderna, vol. 35, pp. 175-222.

Álvarez-Coca González, M.a.J., Latorre Merino, J.L. y Romero Fernández-Pacheco, J.R. (2006). "El Archivo Histórico Nacional. Presente y futuro". RAM. Revista de la Asociación de Archiveros de la Comunidad de Madrid, pp. 16-47.

Arroyal Espigares, P.J. y Martín Palma, M.a T. a (1991). "El Archivo como servicio: instrumentos de control y de difusión". Baetica. Estudios de Arte, Geografía, e Historia, nㅇ 13, pp. 101-118.

Barroso Arahuetes, A. (2008). "Las ventajas de compartir archivos en la web: el servicio digital del AHEB-BEHA". Compartir Archivos. Actas de las VIII Jornadas de archivos aragoneses. Huesca, 25-28 noviembre 2008, pp. 193-206.

Barrueco, J. M. y Subirats Coll, I. (2003). "OAI-PMH: Protocolo para la transmisión de contenidos en Internet". El profesional de la información, v. 12, n. 2, pp. 99-106. Recuperado de http://www. webcitation.org/5cwCcWV1t.

Cruz Mundet, J.R. y Sánchez Mairena, A (2006). "Spanish archival experiences on the Net: the Spanish Archives on the Net Project (AER)". En Aigner, Th. y K. Winter (eds.), Alte Archive - Neue Technologien = Old Archives - New Technologies. St. Pölten: Diözesanarchiv Sankt Pölten, pp. 31-53.

Delgado Gómez, A. (2007). “Metadatos y descripción como representación del contexto archivístico". Ibersid, pp. 157-164.

Desantes Fernández, B. (2004). "Internet y archivos: el Proyecto AER y la Guía electrónica de archivos de España e Iberoamérica". Archivi \& Computer. Automazione e Beni Culturale, no 2, pp. 16-34

Díez de los Ríos, M.a T.a (1996). “El Departamento de Referencias del Archivo Histórico Nacional. Organización y funcionamiento". Boletín de la ANABAD, 46-1, pp. 235-259.

Fox, M. J. (2008). "Resolviendo el rompecabezas de las normas de descripción: encajando las piezas". Tabula, no 11 pp. 19-49.

García González, M.a y Más Bleda, A. (2009). "Los contenidos de las web de los archivos histórico estatales. El ciudadano más cerca de la información".
Cuadernos de Documentación Multimedia, 20. Recuperado de: http://revistas. ucm.es/inf/15759733/articulos/CDMU0909110005A.PDF.

García González, M. a y Chain Navarro, C. (2010). "Acceso a los fondos del Archivo General de Indias a través de la plataforma PARES (Portal de Archivos Españoles)". Naveg@mérica. Revistra electrónica de la Asociación Española de Americanistas, 5. Recuperado de http:// revistas.um.es/navegamerica/article/ view/111481/105831.

García González, M. y Más Bleda, A. (2010). "Pares: portal de archivos españoles. Generando puentes entre el investigador y los fondos archivísticos". Investigación bibliotecológica, vol. 24, no 51. Recuperado de: http://www.scielo.org.mx.

González García, P. (1999). Informatización del Archivo General de Indias. Estrategias y resultados. Madrid: ANABAD. Recuperado de: http://plosjournal.deepdyve.com/.

González García, P. (2003). “¿Archivos Españoles en Red?", Boletín de la ANABAD 53, no 3, pp. 11-36.

Grupo de Expertos IFLA / ICA (2005). Directrices para proyectos de digitalización de colecciones y fondos de dominio público, en particular para aquellos custodiados en bibliotecas y archivos. Madrid: Ministerio de Cultura.

Gutiérrez García, J.M. y Molero Mesa, J. (2007): "Historia de la ciencia e Internet: referencias útiles para el estudio histórico de la veterinaria". Recuperado de http://www.bib.uab.es.

"LUND Principles: conclusions of a meeting of EU-Member States, Lund, 4 April 2001" (2002). Recuperado de ftp://ftp. cordis.europa.eu/pub/ist/docs/digicult/lund_principles-en.pdf.

Méndez Rodríguez, E. (2009). “La biblioteca digital como concepto. Realidad, utopía e índice de contemporaneidad". En Teoría y literatura artística en la sociedad digital: construcción y aplicabilidad de colecciones textuales informatizadas. Gijón: Trea; pp. 25-44.

NORMA para la elaboración de puntos de acceso normalizados en las descripciones de documentos de archivo (2010). Recuperado de http://pares.mcu.es

Oddos, J.-P. (1994). "La numérisation des Archives Générales des Indies à Seville",
Bulletin de la Bibliothéque de France, vol. 39, no 4, pp. 82-86.

REPORT on archives in the enlarged European Union. Increased archival cooperation in Europe: action plan (2005). Brussels: European Commision.

Parra Valcarce, D., Chain Navarro, C. y Sánchez Baena, J.J. (2010). "La divulgación del patrimonio cultural mediante la utilización de la web semántica: un enfoque metodológico", Argos, 27, no 52.

Peset, F. y Ferrer, A. (2008). “Implantación de la Open Archives Initiative en España". IR information research, 13, 4. Recuperado de http://informationr.net/ ir/13-4/paper385.htm

Pons, A. (2008). "A.4. Los servicios de información básicos: logros y retos", Anuario ThinkEPI, pp. 23-26. Recuperado de http://eprints.rclis.org.

Rütimann, H.; Lynn, M. S. (1992). “Computerization Project of the Archivo General de Indias, Seville, Spain". A report to the Commission on Preservation and Access. Washington.. Recuperado de http://www.clir.org/pubs/reports/archivo/archivo.html.

Sánchez Mairena, A. (2008). "Memoria escrita, herramientas electrónicas y fondos archivísticos. Experiencias desde PARES (Portal de Archivos Españoles)". En Compartir Archivos. Actas de las VIII Jornadas de archivos aragoneses (Huesca, 25-28 noviembre 2008). Huesca: Gobierno de Aragón; pp. 115-132.

Sánchez Mairena, A. (2011). "El portal de archivos españoles (PARES) como recurso para la historia local en Internet", Canelobre, 58, pp. 97-106

Santos Canalejo, E. de y Desantes Fernández, B. (2004). "The AER Project (Spanish Archives on the Net)", DigiCULT.Info, 7, pp. 24-28. Recuperado de http://www.digicult.info/downloads/ dc_info_issue7_lowres.pdf.

Simó Rodríguez, M.a I. (2007). "La digitalización en el Archivo General de Indias". IV Congreso de la Lengua Española. Cartagena de Indias. Recuperado de: http://congresodelalengua.es/cartagena/ponencias/seccion 2/27/simo_rodriguez.htm.

Taylor, A.H. (1984). Archival Services and the concept of the user. A RAMP Study. París: Consejo Internacional de Archivos. 